\title{
Road traffic mortality in North Chennai - An autopsy based study
}

\author{
S. Janani ${ }^{1}$, R. Julius ${ }^{2 *}$, S. Balasubramanian ${ }^{3}$ \\ ${ }^{1,2}$ Assistant Professor, ${ }^{3}$ Professor and Head, Dept. of Forensic Medicine \& Toxicology, ${ }^{1,3}$ Government Stanley Medical College, Chennai, \\ Tamil Nadu, ${ }^{2}$ Rajiv Gandhi Government General Hospital and Madras Medical College, Chennai, Tamil Nadu, India
}

*Corresponding Author: R. Julius

Email: janyraj@gmail.com

\begin{abstract}
An accident is an unplanned event that results in injury, deaths, damage to property or some other losses. For statistical purpose, Accidental Deaths have been classified as deaths that could be due to forces/factors of the nature which have been termed as 'Natural Accidental Deaths' or could be due to deliberate or negligent conduct of human beings, which is termed as 'Un-natural Accidental Deaths' or due to causes not covered in the above two categories and with no initial apparent cause of deaths which have been categorised as 'Other Causes of Deaths' like poisoning, sudden death etc. (1) India has a well-knit and coordinated system of transport which plays an important role in development of economic activities by promoting fair distribution of produced goods and services. The share of transport sector in Gross Domestic Product (GDP) of India is steadily growing. It is one of the key indicators in assessment of socio-economic development of the country. Tamil Nadu has reported for $9.8 \%$ of total deaths in traffic accidents reported at all India level in the year 2015. (1) The present study was conducted to analyze the socio-demographic and clinical profile of deaths due to road accidents which were brought to the Department of Forensic Medicine for autopsy during the year 2019. Road traffic accidents is a well-known causative and contributer to a high number of mortality and morbidity. Urbanisation leading to widening of roads, increase in motor vehicles are among the few contributing factors to the increase in number of road accidents. Males in the productive age group being the most common victims is also a well documented fact. In this study, we observed a high number of fatalities in the National highways and the service roads connecting the nearby villages. Also we observed maximum fatalities in accidents that occurred in the mid - day and evening when they are mostly on their way back home from work. Apart from strict regulations, it is the individual's awareness and preventive strategies that will help in reducing such wastage of precious life. It is time we make the younger generations to remember and realise that it is better late than to be never.
\end{abstract}

Keyword: Road accident, Mortality, Head injury.

\section{Introduction}

An accident is an unplanned event that results in injury, deaths, damage to property or some other losses. For statistical purpose, Accidental Deaths have been classified as deaths that could be due to forces/factors of the nature which have been termed as 'Natural Accidental Deaths' or could be due to deliberate or negligent conduct of human beings, which is termed as 'Un-natural Accidental Deaths' or due to causes not covered in the above two categories and with no initial apparent cause of deaths which have been categorised as 'Other Causes of Deaths' like poisoning, sudden death etc. ${ }^{1}$ India has a well-knit and coordinated system of transport which plays an important role in development of economic activities by promoting fair distribution of produced goods and services. The share of transport sector in Gross Domestic Product (GDP) of India is steadily growing. It is one of the key indicators in assessment of socio-economic development of the country. Tamil Nadu has reported for $9.8 \%$ of total deaths in traffic accidents reported at all India level in the year 2015. ${ }^{1}$ The present study was conducted to analyze the sociodemographic and clinical profile of deaths due to road accidents which were brought to the Department of Forensic Medicine for autopsy during the year 2019.

\section{Objectives}

1. To study the incidence of deaths due to road traffic accidents
2. To study the demographic profile of road accident victims

3. To study the different types of vehicles involved in fatal accidents

4. To study the pattern of injuries in fatal road accidents.

\section{Materials and Methods}

The present study was a cross sectional retrospective study done in the department of Forensic Medicine \& Toxicology. All autopsies done on road accident victims during the period Jan to Dec 2019 were studied. Data about demographics and circumstances of incidence were obtained from the inquest papers. Information about distribution of injuries and cause of death were obtained from post-mortem reports and treatment papers. All data were entered in proforma and analysed using statistical software and tabulated.

\section{Inclusion criteria}

Death due to road accident.

\section{Exclusion criteria}

Death due to any cause other than road accident.

\section{Study period}

January to December 2019. 


\section{Results and Discussion}

Table 1: Sex wise distribution of cases

\begin{tabular}{|l|c|}
\hline Sex & No. of cases \\
\hline Male & $278(92 \%)$ \\
\hline Female & $25(8 \%)$ \\
\hline Total & 303 \\
\hline
\end{tabular}

In the present study $92 \%$ of the victims were male and the remaining $25 \%$ were females, with a ratio of $7: 1$. This is similar to other Indian and international studies published. ${ }^{2-5}$

Table 2: Age wise distribution of cases

\begin{tabular}{|l|c|}
\hline Age & No. of cases \\
\hline $0-10$ & $4(1 \%)$ \\
\hline $11-20$ & $29(9 \%)$ \\
\hline $21-30$ & $72(24 \%)$ \\
\hline $31-40$ & $52(17 \%)$ \\
\hline $41-50$ & $49(16 \%)$ \\
\hline $51-60$ & $56(18 \%)$ \\
\hline $61-70$ & $29(9 \%)$ \\
\hline $71-80$ & $10(3 \%)$ \\
\hline $81-90$ & $2(0.6 \%)$ \\
\hline Total & 303 \\
\hline
\end{tabular}

Maximum victims were in the productive age group, $24 \%$ were of $21-30$ years and $17 \%$ in $31-40$ years. $18 \%$ of the victims were in the age group of 51-60years. The victims were in the age group from 5 months to 87 years, with a mean age 41 years. This is in concurrence with similar studies in other parts of India and abroad. ${ }^{2-5}$

Table 3: Distribution of cases according to place of accident

\begin{tabular}{|l|c|}
\hline Place of accident & Number of cases \\
\hline National highways & 130 \\
\hline State highways & 92 \\
\hline Small road & 80 \\
\hline Other & 1 \\
\hline Total & 303 \\
\hline
\end{tabular}

In the present study, $43 \%$ of the accidents were reported to have occurred at one of the National highways in the city. $30 \%$ of the accidents had occurred in the state highways and the remaining accidents in the connecting roads within the city. One accident had occurred inside a construction site, in which a construction worker was hit by a dumper truck. A greater proportion of accidents have been reported to have occurred in urban regions when compared to rural regions in other studies as well. ${ }^{2-4}$

The tertiary care centre where the study was conducted caters to a large population of Northern Chennai. The nearby residential areas are well connected by means of State and National highways apart from state given small roads. To avoid rush hour traffic, a lot of people are now willing to take even a longer route if it goes through state /national highways due to ease of travel. Also availability of online maps and navigation has opened many unexplored routes to the common public. The lack of necessity to stop and enquire the way ahead has also increased the speed and rashness of commute resulting in accidents.

Table 4: Distribution of cases according to time of accident

\begin{tabular}{|l|c|}
\hline Time of accident & Number of cases \\
\hline $12-4 \mathrm{am}$ & 28 \\
\hline $4-8 \mathrm{am}$ & 36 \\
\hline $8-12$ noon & 33 \\
\hline $12 \mathrm{noon}-4 \mathrm{pm}$ & 58 \\
\hline $4-8 \mathrm{pm}$ & 125 \\
\hline $8 \mathrm{pm} \mathrm{-12am}$ & 23 \\
\hline Total & 303 \\
\hline
\end{tabular}

For convenience sake, a day was divided into 6 parts; Midnight (12am to 4am), early morning (4-8am), morning (8am-12noon), mid-day (12noon-4pm), evening (4-8pm) and night $(8 \mathrm{pm}-11.59 \mathrm{pm}) .41 \%$ of the accidents had occurred evening, followed by $19 \%$ (58 cases) which had occurred in the mid-day.

Singh et $\mathrm{al}^{2}$ and Shruthi at $\mathrm{al}^{3}$ have reported maximum number of accidents in the time period of 6am to 12 noon. In the present study maximum numbers of cases were seen in the evening time which is the time when a normal day worker returns home. Chennai and its vicinity have seen a gradual increase in number of educational institutions in the past decade. Also people are now willing to invest in purchase own property in far of place rather than live in a rental accommodation near their workplace. Majority of the institutions work till four after when, all their individual and group transport means like buses are allowed to leave the campus. This sudden acute addition of vehicles to the already existing flow of traffic is possibly a reason to the increase in number of cases in the evening time.

Table 5: Distribution of cases according to vehicle involved

\begin{tabular}{|l|c|}
\hline Vehicle & Number of cases \\
\hline Pedestrian & 74 \\
\hline Two wheeler & 213 \\
\hline Four wheeler & 2 \\
\hline Heavy vehicle & 3 \\
\hline Others & 11 \\
\hline Total & 303 \\
\hline
\end{tabular}

$70 \%$ of the victims involved were in a two wheeler at the time of accidents and most of them were driving the vehicle. $24 \%$ of the victims were pedestrians. Pedestrians were hit by two wheelers, four wheelers, heavy vehicles and unknown vehicles. Pedestrians were the commonest victims in a study done by Singh et $\mathrm{al}^{2}$ whereas four wheelers were reported to have been commonly involved in the study analysed by Shruthi et al. ${ }^{3}$ In the present study two wheelers (both drivers and pillion riders) were the most commonly involved vehicles. Two wheelers are easier to navigate in congestion and are also fuel efficient. This along with the lack of parking spaces for four wheelers makes two wheelers an easier option for the young and old alike. Also, 
the younger generations opting for fancy vehicles and engaging in unlawful racing activities have also contributed to road accident mortalities.

Table 6: Distribution of cases according to time between incidence and death

\begin{tabular}{|l|c|}
\hline Vehicle & Number of cases \\
\hline Brought dead to hospital & 151 \\
\hline Less than 6 hours & 21 \\
\hline Less than 7 days & 104 \\
\hline 1 to 2 weeks & 17 \\
\hline 2 to 4 weeks & 8 \\
\hline More than 1 month & 2 \\
\hline Total & 303 \\
\hline
\end{tabular}

Half of the victims $(50 \%)$ were brought dead to the hospital. Of the others, a majority (34\%) survived for less than a week. Similar numbers have been reported in studies done in Fiji ${ }^{4}$ and Multan. ${ }^{5}$ This could be attributed to the severity of injuries sustained which indirectly reflects the magnitude of imnpact.

Table 7: Distribution of cases according to cause of death

\begin{tabular}{|l|c|}
\hline Cause of death & Number of cases \\
\hline Head injuries & 179 \\
\hline Neck (spinal injury) & 3 \\
\hline Multiple injuries & 69 \\
\hline Chest and abdomen & 52 \\
\hline Total & 303 \\
\hline
\end{tabular}

Head injury was the cause of death in $59 \%$ of the cases. The second most common cause was multiple injuries in which more than one body cavity was involved with /without limb involvement $(22 \%)$. Hemorrhage due to thoraco-abdominal injuries was seen in $17 \%$ of the cases. Head injury being the commonest cause of death has been reported in India and abroad widely. ${ }^{2-5}$ Despite the recent regulations forcing both the driver and pillion rider to wear helmet, head injury remains to be the single most common cause of death in road accident victims. Though this could be attributed to the casual attitude of public many of who use helmets just to escape penalty, there have been many instances where even helmet couldn't save the victim in severe crush injuries and run over injuries.

\section{Discussion}

Road traffic accidents is a well-known causative and contributer to a high number of mortality and morbidity. Urbanisation leading to widening of roads, increase in motor vehicles are among the few contributing factors to the increase in number of road accidents. Males in the productive age group being the most common victims is also a well documented fact. In this study, we observed a high number of fatalities in the National highways and the service roads connecting the nearby villages. Also we observed maximum fatalities in accidents that occurred in the mid - day and evening when they are mostly on their way back home from work. Apart from strict regulations, it is the individual's awareness and preventive strategies that will help in reducing such wastage of precious life. It is time we make the younger generations to remember and realise that it is better late than to be never.

\section{Source of Funding}

None.

\section{Conflict of Interest}

None.

\section{References}

1. Accidental Deaths \& Suicides in India 2015. National crime records bureau, Ministry of Home Affairs, Government of India.

2. Singh YN, Bairagi KK, Das, KC. An epidemiological study of road traffic accident victims in medicolegal autopsies. JIAFM. 2005;27(3):166-9.

3. Shruthi P, Venkatesh VT, Viswakanth B, Ramesh C, Sujatha PL, Dominic IR. Analysis of fatal road traffic accidents in a metropolitan city of South India. Indian Acad Forensic Med. 2013;35(4):317-20.

4. Kalougivaki JJVP, Goundar RPS. Retrospective autopsy based study of fatal road traffic accidents in Fiji. J Forensic Res. 2014;5:243.

5. Arif M, Ahmed M, Rasool SH. Road traffic accidents; autopsy based study in Multan. Professional Med J. 2015;22(5):621-6.

How to cite this article: Janani $\mathrm{S}$, Julius $\mathrm{R}$, Balasubramanian S. Road traffic mortality in North Chennai - An autopsy based study. Indian J Forensic Community Med. 2020;7(1):4-6. 